\title{
Enabling Conditions for Improved Use of Seasonal Climate Forecast in Arid and Semi-Arid Baringo County-Kenya
}

\author{
Richard Ochieng1* ${ }^{*}$ Charles Recha ${ }^{1}$, Bockline Omedo Bebe ${ }^{2}$ \\ ${ }^{1}$ Department of Geography, Egerton University, Kenya \\ ${ }^{2}$ Department of Animal Sciences, Egerton University, Kenya \\ Email: ^snrochieng@gmail.com, charles.recha@egerton.ac.ke, bbebe@egerton.ac.ke
}

How to cite this paper: Ochieng, R., Recha, C. and Bebe, B.O. (2017) Enabling Conditions for Improved Use of Seasonal Climate Forecast in Arid and Semi-Arid Baringo County-Kenya. Open Access Library Journal, 4: e3826.

https://doi.org/10.4236/oalib.1103826

Received: July 14, 2017

Accepted: August 1, 2017

Published: August 4, 2017

Copyright $\odot 2017$ by authors and Open Access Library Inc.

This work is licensed under the Creative Commons Attribution International License (CC BY 4.0).

http://creativecommons.org/licenses/by/4.0/

\begin{abstract}
The use of seasonal climate forecasts can inform implementation of planned adaptation strategies to stabilize pastoral livestock assets in drought prone agro ecological zones. The main objective of this study was to assess use of seasonal climate forecasts as strategies for securing pastoralists assets in arid and semi-arid lands (ASALs) of Baringo County. The study used five (5) study locations that were purposively picked to ensure that they fall within the ASAL agro-ecological zones, LM5 and IL6. The total sampled households from the five locations was 221 . The study used data from household survey to establish barriers to use of seasonal climate forecasts, use of traditional climate information and enabling conditions. Mean comparisons and frequencies of ratings were generated to ascertain the use of traditional climate information among the respondents. Sensitivity analysis was useful in identifying the most significant barriers to uptake of seasonal climate forecasts and the best and most significant enabling conditions/institutions to the access and usage of climate forecasts. The study established that majority (72.4\%) of the respondents relied on traditional climate forecast methods than scientific methods in decision-making. The factors with greater influence on uptake of seasonal climate forecast information were lack of information, access, diversified sources of income and insecurity/conflicts, illiteracy and culture. The institutions with large influence were knowledge dissemination linked to radio and extension services and local climate information. The study recommends increased investments in strengthening and equipping human resource capacities of the pastoral community, local weather stations and extension services to foster uptake of scientific climate information to help reduce vulnerability to drought events in the arid and semi-arid lands.
\end{abstract}




\section{Subject Areas}

Natural Geography

\section{Keywords}

Drought Events, Arid and Semi-Arid Lands, Seasonal Climate Forecasts, Enabling Conditions

\section{Introduction}

Studies indicates that seasonal climate forecasts if accessed at the right time and used well, are a potential tool that can assist pastoralists in coping and adapting to variable climate conditions [1] [2] [3]. Effective climate information services for the pastoralist communities involve improving information products, information services and delivery of those products. According to [4], pastoralists can best use climate forecast information when: it is interpreted at a local scale and includes information about timing beyond seasonal climate means; expressed accurately in transparent and probabilistic terms; and can be interpreted in terms of impacts and management implications. Effective use of climate information requires that raw climate information be translated into quantitative information (water status, pest or disease risk, vegetation and yields) with uncertainties expressed in probabilistic terms [4]. Useful seasonal forecasts are those produced and disseminated with the user in mind as they aim at benefiting production if continuously and effectively used [1]. The forecasts should be communicated in a manner that is comprehensible to the end users, and addressing the local needs of pastoralists for whom the seasonal rains have critical importance [5] [6] [7].

Though there is wide group of potential end users, only a relatively small fraction of the total number of individual users usually benefit from seasonal climate forecasts. Some farmers view probabilistic forecasts as unrealistic expectations and broken promises. More so, lack of resources among farmers critically limit their range of choice in terms of alternative options, technologies or cash generating activities [5] [8].

Drought events are a threat to pastoralism and its effects vary over time and space, calling for more studies to generate information that can be used to guide appropriate decision making, reduce vulnerability and secure the livelihoods of the pastoral community [9]. The present study sought to identify opportunities for implementation of seasonal climate forecasts as an adaptation strategy in Arid and Semi-Arid lands. The information generated will help improve the adaptive capacity of the pastoralists in similar environmental conditions. The present study is anchored on past studies that recommended further research on the use of seasonal climate forecasting by pastoral communities, with keen focus on the pastoralists' ability to access, trust and respond to the forecasts [10] [11]. 
The study sought to strengthen the resilience of ASAL communities to drought and other climate related disasters, an objective of the ASAL policy and other legislations. Successful achievement of transforming the ASALs will be measured based on the attention given to the distinct challenges facing the region and a shift from focusing at the ASALS as net consumers of the national wealth [12] [13].

\section{Study Area}

Baringo County (Figure 1) is located within the Rift Valley of Kenya, between longitudes $35^{\circ} 30^{\prime}$ and $36^{\circ} 30^{\prime}$ East and between latitudes $0^{\circ} 10^{\prime}$ South and $1^{\circ} 40^{\prime}$ North. The County covers an area of $11,090 \mathrm{Km}^{2}$ with a population of 555,561 persons. The agro-ecological zones in the county are: UH 1, UH 2, LH 2, LH 3 , UM 3, UM 4, UM 5, LM 4, LM 5, LM 6 and IL 6. Temperatures range from a minimum of $10^{\circ} \mathrm{C}$ to a maximum of $35.0^{\circ} \mathrm{C}$ with bimodal rainfall pattern of long rains (MAM) and short rains (OND) which range from 300 to $700 \mathrm{~mm}$ in the lowlands and $1200 \mathrm{~mm}$ in the highlands [14] [15]. The main livestock in the County include the East African Zebu cattle in the lowlands and exotic cattle in the highlands. The crops grown are: Maize, finger millet, sorghum, beans, cowpeas, green grams, Irish potatoes and sweet potatoes [16].

The choice of Baringo County as a study area was based on the findings of previous studies that revealed that rainfall variability and drought has significantly impacted on the rural smallholder farmers and pastoral community who rely mostly on rainfall for agricultural production and sustenance of livelihoods [17]. Baringo County, one of the ASALs, has been hit by cycles of frequent and severe droughts impacted negatively on the pastoral livelihoods [18] [19]. To

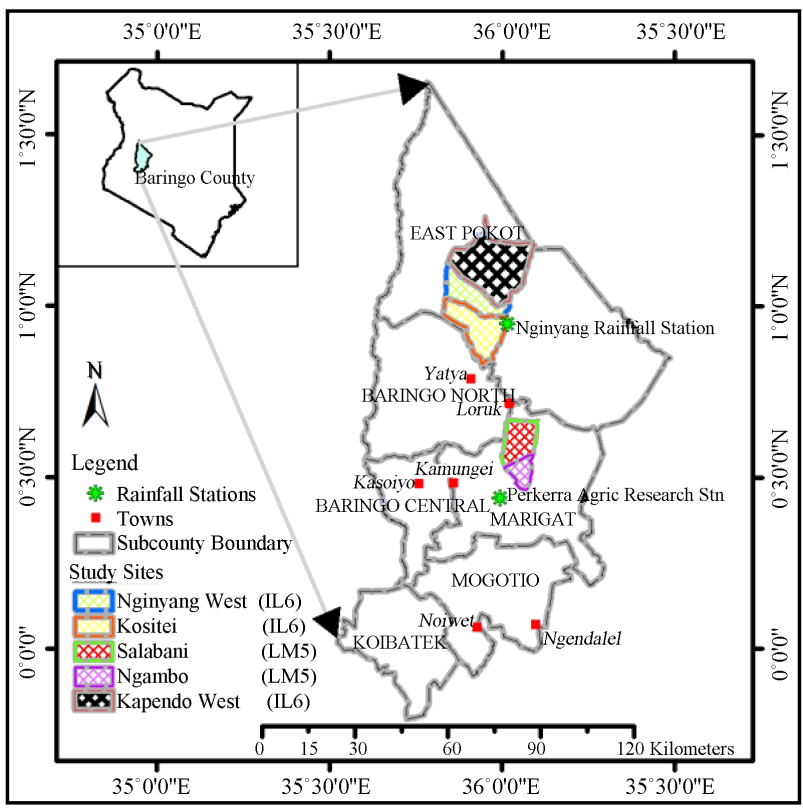

Figure 1. Map showing study locations and rainfall stations. Source: Author, 2016. 
adequately address the effects of drought and reduce vulnerability among the pastoral community, there was need to carry out location-specific research focusing on the ASAL Baringo County. This is significant in developing appropriate adaptation strategies to reduce vulnerability to drought among pastoral community in the study area. The primary policy challenge involves approaches through which food and nutrition security can be guaranteed in the ASALs, Baringo County included, in a sustainable manner [12].

\section{Materials and Methods}

The study employed cross sectional survey design for primary data obtainable from pastoral households. Questionnaire was used to collect household data from sampled population from agro-ecological zones LM5 and IL6. The two agro-ecological zones were purposively chosen as the study targeted the extreme semi-arid and arid parts of Baringo County. The study used five (5) study locations that were also purposively picked to ensure that they fall within the ASAL agro-ecological zones, LM5 and IL6. The total sampled households from the five locations was 221 . The sample was proportionately distributed across the two agro-ecological zones (LM5 and IL6). Cross sectional household survey was used to collect data on usage and condition enabling utilization of seasonal climate forecast. Mean comparisons, frequencies and ratings were generated to establish usage of traditional climate information.

The study used sensitivity analysis (effectiveness test computed as $A /(A+C)$ to identify the main barriers and enabling conditions to uptake of seasonal climate forecasts. Variables with effectiveness values greater than 0.5 (50\%) were extracted as the most significant variables that facilitate or hinder uptake of seasonal climate forecasts. Table 1 and Table 2 shows the variables considered in the analysis.

\section{Results and Discussions}

\subsection{Enabling Conditions for Utilization of Seasonal Climate Forecasts by the Pastoral Households}

\subsubsection{Barriers to Use of Scientific Seasonal Climate Forecasts}

The study further sought to determine the hindrances to use of scientific seasonal climate forecasts to inform decision making regarding drought events. Table 3 presents the study findings.

The study identified six hindrances to scientific climate information. These include lack of access to seasonal climate forecasts $(e=0.98)$, culture $(e=0.98)$, lack of diversified sources on income ( $e=0.72$ ), illiteracy ( $e=0.89$ ), lack of information $(e=0.81)$ and insecurity/conflicts $(e=0.96)$. The sensitivity analysis was significant in identifying the critical variables that hinder uptake of seasonal climate forecast information.

Interview findings confirmed that there is a high degree of illiteracy in the study area with sensitivity test indicating a probability of $89 \%$ chance of illiteracy 
Table 1. Hindrances to use of seasonal climate forecasts to respond to drought events.

\begin{tabular}{ccccc}
\hline \multicolumn{5}{c}{ Uptake of seasonal climate forecast } \\
\hline & Yes & No & Total \\
\hline & Positive/True & $\mathrm{A}_{i}$ & $\mathrm{~B}_{i}$ & $\mathrm{~A}_{i}+\mathrm{B}_{i}$ \\
& & & (Total number of subjects with positive test for each the 9 variables) \\
& Total & $\mathrm{C}_{i}$ & $\mathrm{D}_{i}$ & (Total number of subjects with negative test for each of the 9 variables) \\
& $\mathrm{A}_{i}+\mathrm{C}_{i}$ & $\mathrm{~B}_{i}+\mathrm{D}_{i}$ & $\mathrm{~A}_{i}+\mathrm{B}_{i}+\mathrm{C}_{i}+\mathrm{D}_{i}$ \\
\hline
\end{tabular}

Source: Zhu, Zeng \& Wang (2010); Author, 2017. Where: $i=1$ to 9 . A = Number of respondents who use seasonal climate forecasts and more so consider variable $i$ hindrance to uptake of seasonal climate forecast (True positive). B = Number of respondents who do not use seasonal climate forecasts but consider variable $i$ hindrance to uptake of seasonal climate forecast (False positive). $\mathrm{C}=$ Number of respondents who use seasonal climate forecasts but do not consider variable $i$ hindrance to uptake of seasonal climate forecast (False negative). $\mathrm{D}=$ Number of respondents who do not use seasonal climate forecasts and more so do not consider variable $i$ hindrance to uptake of seasonal climate forecast (True Negative).

Table 2. Enabling institution for scientific climate information.

\begin{tabular}{ccccc}
\hline & & \multicolumn{3}{c}{ Uptake of seasonal climate forecast } \\
\hline & Yes & No & Total \\
\hline & Positive/True & $\mathrm{A}_{i}$ & $\mathrm{~B}_{i}$ & $\mathrm{~A}_{i}+\mathrm{B}_{i}$ \\
& Negative/False & $\mathrm{C}_{i}$ & $\mathrm{D}_{i}$ & (Total number of subjects with positive test for each the 5 variables) \\
(Total number of subjects with negative test for each of the 5 variables) & $\mathrm{C}_{i}+\mathrm{D}_{i}$ \\
& Total & $\mathrm{A}_{i}+\mathrm{C}_{i}$ & $\mathrm{~B}_{i}+\mathrm{D}_{i}$ & $\mathrm{~A}_{i}+\mathrm{B}_{i}+\mathrm{C}_{i}+\mathrm{D}_{i}$
\end{tabular}

Source: Zhu, Zeng \& Wang (2010); Author, 2017. Where: $i=1$ to 5 . A = Number of respondents who use seasonal climate forecasts and more so consider variable $i$ enabling condition to uptake of seasonal climate forecast (True positive). B = Number of respondents who do not use seasonal climate forecasts but consider variable $i$ enabling condition to uptake of seasonal climate forecast (False positive). C = Number of respondents who use seasonal climate forecasts but do not consider variable $i$ enabling condition to uptake of seasonal climate forecast (False negative). D = Number of respondents who do not use seasonal climate forecasts and more so do not consider variable $i$ enabling condition to uptake of seasonal climate forecast (True Negative).

hindering uptake of seasonal climate forecast. The education situation is poor as the children and the young men rarely get the opportunity to study. Results from the socio-economic data of the respondents, which indicated that $42 \%$ of all the respondents had no formal education while $31 \%$ had only primary school level of education supports this finding. This implies that illiteracy among the pastoralist community is very high with nearly half of the respondents lacking any formal education. From the interviews, the study established that the main cause of low literacy in these communities was lack of external support for education from either the government or other institutions/organizations in terms of teachers, educational materials and schools. The other reasons were the constant movement of communities subjecting them to limited time for accessing formal education, low value placed on education by the communities, poor security and ongoing cattle rustling. The low literacy levels in the study areas negatively affect the level of awareness, access and uptake for any new alternative or scientific technology, knowledge or information. This is because lack of formal education creates a barrier to acceptance of new technologies. Communities with high rate of illiteracy put more value on indigenous knowledge than scientific knowledge hence creating a barrier to uptake of non-indigenous information. Such communities will not readily participate in workshops or seminars that focus on 
Table 3. Hindrances to use of seasonal climate forecasts to respond to drought events.

\begin{tabular}{|c|c|c|c|c|c|c|}
\hline & \multicolumn{6}{|c|}{ Uptake of seasonal climate forecast } \\
\hline & & & Yes & No & Total & $\begin{array}{c}\text { Effectiveness } \\
\text { (e) }\end{array}$ \\
\hline \multirow{18}{*}{ 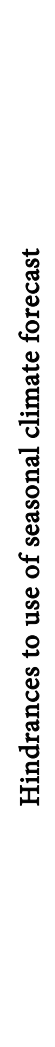 } & \multirow{2}{*}{$\begin{array}{l}\text { Gender related } \\
\text { disadvantages }\end{array}$} & True/Positive & 23 & 71 & 94 & \multirow{2}{*}{$e=0.40$} \\
\hline & & False/Negative & 34 & 93 & 127 & \\
\hline & \multirow{2}{*}{$\begin{array}{l}\text { Lack of access to } \\
\text { seasonal climate } \\
\text { forecasts }\end{array}$} & True/Positive & 56 & 155 & 211 & \multirow{2}{*}{$e=0.98$} \\
\hline & & False/Negative & 01 & 09 & 10 & \\
\hline & \multirow{2}{*}{$\begin{array}{l}\text { Age of household } \\
\text { head }\end{array}$} & True/Positive & 28 & 121 & 149 & \multirow{2}{*}{$e=0.49$} \\
\hline & & False/Negative & 29 & 43 & 72 & \\
\hline & \multirow{2}{*}{ Culture } & True/Positive & 56 & 63 & 119 & \multirow{2}{*}{$e=0.98$} \\
\hline & & False/Negative & 01 & 101 & 102 & \\
\hline & \multirow{2}{*}{$\begin{array}{l}\text { Lack of diversified } \\
\text { sources of income }\end{array}$} & True/Positive & 41 & 153 & 194 & \multirow{2}{*}{$e=0.72$} \\
\hline & & False/Negative & 16 & 11 & 27 & \\
\hline & \multirow{2}{*}{$\begin{array}{l}\text { Unavailability of } \\
\text { credit }\end{array}$} & True/Positive & 27 & 143 & 170 & \multirow{2}{*}{$e=0.47$} \\
\hline & & False/Negative & 30 & 21 & 51 & \\
\hline & \multirow{2}{*}{ Illiteracy } & True/Positive & 51 & 158 & 209 & \multirow{2}{*}{$e=0.89$} \\
\hline & & False/Negative & 06 & 06 & 12 & \\
\hline & \multirow{2}{*}{ Lack of information } & True/Positive & 46 & 150 & 196 & \multirow{2}{*}{$e=0.81$} \\
\hline & & False/Negative & 11 & 14 & 25 & \\
\hline & \multirow{2}{*}{ Insecurity/conflicts } & True/Positive & 55 & 158 & 213 & \multirow{2}{*}{$e=0.96$} \\
\hline & & False/Negative & 02 & 06 & 08 & \\
\hline
\end{tabular}

Source: Author, (2017).

non-indigenous technologies, making over-reliance on indigenous knowledge a hindrance to use of scientific information. [20] established that farmers who attended workshops about seasonal climate forecasts were significantly more likely to use the forecasts, a finding that supports the conclusion of the present study. This may be the main reason why lack of information $(e=0.81)$ and access of seasonal climate forecasts $(e=0.98)$ are amongst the major hindrances to use of SCFs in the study area. [21] recorded similar findings among pastoralist communities in Southern Ethiopia and Northern Kenya, and [22] who assessed the use of indigenous knowledge among the Mahenge and Ismani communities in Tanzania. Each community had various early warning indicators that is widely accepted among members of the community. Such knowledge through guidance of council of elders are useful in responding efficiently to environmental disasters, making the community to bestow value upon the approaches [23]. Among the Banyala community of Budalangi, elders over time have dealt with rainfall prediction and early warning signs, an activity that the community appreciates [23]. Communities that have depended on indigenous knowledge believes that neglect may lead to environmental deterioration while appropriate uptake is a 
guarantee to environmental conservation. The place of indigenous knowledge and culture $(e=0.98)$ poses threats to uptake of scientific seasonal climate forecasts amongst the pastoral communities. [24] indicates that there is urgent need to review the strengths and weaknesses of local and scientific knowledge of climate change and the potential complementarity of local and scientific knowledge.

The study established that insecurity and conflicts $(e=0.96)$ is a major hindrance to uptake of seasonal climate forecast. From the interview, the respondents reported that the problem of insecurity and clashes has become a major problem to pastoralists in the extent of ranking it above drought events. This has made them spent most of their time and resources to reduce their vulnerability towards the same at the expense of new technologies. According to [25], analysis of undercurrents of ethnic conflicts in Kenya, ethnic tensions developed especially around the structure of access to economic opportunities and redistribution of some of the land formerly owned by the white settlers. Most of the land in question is in former Rift Valley Province and historically settled by the Kalenjin and the Maasai. Cases of ethnic clashes erupted towards the end of 1991 and targeted non-Kalenjin, Maasai, Turkana and Samburu inhabitants [26]. Cases of people killed and livestock stolen still appear frequently in the local press reports. However, the most effective strategy employed by the perpetrators is the destruction of homes and property of the victims in the hope that they would flee to their "ancestral lands" [27]. Most respondents cited grazing land and cattle rustling as the main cause of ethnic conflicts or tension in the study area. Other main causes mentioned in the interviews include political incitements, racism, poverty and traditions. The perception that there is unequal distribution of resources especially land is largely responsible for the ethnic conflicts that took place in the study area in 1992, 1997 and 2006 when some ethnic communities were armed to raid and destroy belonging to other ethnic communities [25] [27], a problem that affected all ethnic groupings including the pastoralist.

The study established that lack of diversified sources of income has an effectiveness of 0.72 (probability of $72 \%$ ) hindering uptake of seasonal climate forecast as a decision making tool with regard to response to drought events. The study attributes the finding to lack of economic capital, which limits respondents' ability to engage in alternative economic activities in times of drought events, and therefore do not appreciate the access and use of seasonal climate forecasts.

When asked what can be done to improve their access to climate forecast information, almost all the respondents (98\%) recommended that local leaders, Barazas (public meeting), extension officers, workshops and seminars should be used in educating the residents and disseminating climate information. The inconsistent access of these forecasts may have resulted in most respondents not having knowledge about the forecasts, affecting its ultimate uptake. 
On the need for additional forecasting information, the interview results revealed that information such as the on-set and ending of the rains as well as the possibility and timing of a drought would be handy to the respondents (these information is currently provided by KMS and NDMA). Droughts are dreaded climatic phenomena in the survey area and therefore, any information on when the next drought is likely to strike is very important in decision making regarding the appropriate adaptation strategies. From the interview results, most of the respondents indicated that, drought-specific information potentially influenced their strategic decisions on water, food and fodder conservation.

\subsubsection{Use of Traditional Climate Information}

Traditional climate information is based on the communities' indigenous knowledge in interpreting and making decision related to climate. A majority of the sample population (95\%) were aware of the indigenous knowledge of climate forecasting. This high awareness relates to more reliance $(72.4 \%)$ upon traditional climate forecast methods than the scientific methods (Figure 2). According to them, they have relied on this information through the generations, they have remained valuable tools, and therefore majority (94\%) give priority to information from indigenous climate forecast methods. However, about one fifth (21.27\%) reported combining traditional and scientific forecasts in the face of changing climatic conditions. According to [28], information from indigenous weather forecasting methods with modern forecasting science can build up climate change intelligence and help make the data accessible to both pastoralists and subsistence farming communities.

Pastoralists use various indigenous strategies of climate forecasting including observing changes in trees, sky, moon, wind and behaviour of animals. Sometimes, they use other traditional indicators including animal intestines (Haruspication), bird movements, animal behaviour, butterflies, wind direction, heat

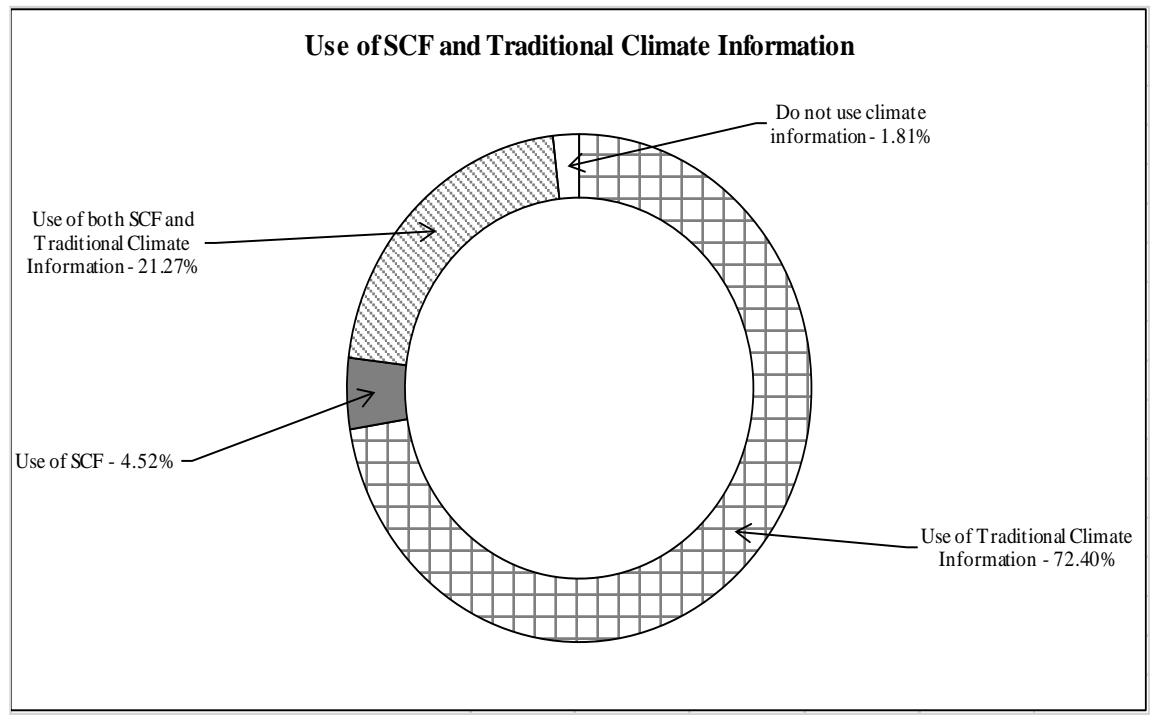

Figure 2. Usage of SCF and traditional climate information. Source: Author, 2016. 
patterns and use of heavenly formation of stars. Different animals and insects display certain behaviours on the onset of the rainy seasons, for instance, the chirping of insects like cicadas (Cryptotympana postulata) and crickets (Gryllus sp.) was associated with high temperatures at the beginning of the rainy season. The sample population indicated that mosquitoes would be most active during hot periods just before rainfall onset when they bite more.

\subsubsection{Enabling Institution}

Table 4 shows five enabling institutions assessed to identify which of them have a greater influence on the dissemination, access and uptake of scientific climate information.

Use of effectiveness test in sensitivity analysis extracted three enabling institutions with effectiveness (e-value) greater than 0.5. Effectiveness measures the probability of an identified enabling condition influencing the uptake of seasonal climate forecasts. These include media ( $e$-value $=0.79$ ), extension services $(e$-value $=0.56)$, and local climate information $(e$-value $=0.81)$. The study attributes the high use and identification of the effectiveness of media by respondents to the fact that $81 \%$ of respondents owned radios and $15 \%$ had access to daily newspapers. Only $4 \%$ of the respondents owned televisions. This forms a good avenue for dissemination and access of scientific climate information. High access and penetration of media amongst the pastoralist community provides the best platform for enlightening the target population of the significance of scientific climate information and distribution of the forecast.

Extension services $(e$-value $=0.56)$ indicates $56 \%$ chance of influencing uptake of scientific climate information. The relatively low effectiveness value ( $e$-value $=$ 0.56) can be attributed to weak extension structures in the study area. In a study to examine the effectiveness of seasonal climate forecasts and regional climate-risk management strategies in Southern Africa, [29] established that exten-

Table 4. Enabling institution for scientific climate information.

\begin{tabular}{|c|c|c|c|c|c|c|}
\hline & \multicolumn{6}{|c|}{ Uptake of seasonal climate forecast } \\
\hline & & & Yes & No & Total & Effectiveness (e) \\
\hline \multirow{10}{*}{ 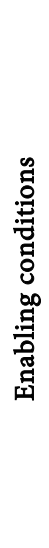 } & \multirow{2}{*}{ Media } & True/+ve & 45 & 142 & 187 & \multirow{2}{*}{$e=0.79$} \\
\hline & & False/-ve & 12 & 22 & 34 & \\
\hline & \multirow{2}{*}{ Extension services } & True/+ve & 32 & 108 & 140 & \multirow{2}{*}{$e=0.56$} \\
\hline & & False/-ve & 25 & 56 & 81 & \\
\hline & \multirow{2}{*}{$\begin{array}{l}\text { Local climate } \\
\text { information }\end{array}$} & True/+ve & 46 & 139 & 185 & \multirow{2}{*}{$e=0.81$} \\
\hline & & False/-ve & 11 & 25 & 36 & \\
\hline & \multirow{2}{*}{ Laws and policies } & True/+ve & 15 & 45 & 60 & \multirow{2}{*}{$e=0.26$} \\
\hline & & False/-ve & 42 & 109 & 151 & \\
\hline & \multirow{2}{*}{$\begin{array}{c}\text { Research } \\
\text { organizations }\end{array}$} & True/+ve & 24 & 62 & 86 & \multirow{2}{*}{$e=0.42$} \\
\hline & & False/-ve & 33 & 102 & 135 & \\
\hline
\end{tabular}

Source: Author, 2017 
sion agents that are weak operationally, affects the flow of climate information between the producers of the information to end users. [30] in a study to assess the changing role of agricultural extension in a global economy, acknowledges the importance of extension services shifting from food security to increasing farm income, an indication that extension services has an important role to play in livestock production. A strong extension service system should not only exist by name but must refocus on getting farmers organised through building social capital, forming a channel though which climate forecasts is disseminated, increasing farm income and help alleviate rural poverty [30]. The role of such systems is to meet the needs of the rural pastoral community.

According to [31] [32] [33] [34], many farmers have little contact with agricultural extension agents and therefore cannot depend on receiving timely information from them. Despite the ailing status of agricultural extension in many countries, traditional agricultural extension and para-extension may still be useful as a means of disseminating climate information and provide insights into better climate risk management [29]. [35] in their study among the smallholder agro-pastoralists in Machakos County found that inter-personal contacts were the most common source of climate forecast information due to the absence of other sources such as radio or television. In pursuit to empower the pastoral communities, field extension offices have a duty to access up to date information and disseminate the same to the farmers [30]. These findings confirm that extension services if well utilized can be an effective and significant institution in influencing uptake of scientific climate information. [36] in a study among Gascoyne-Murchison pastoralists in Western Australian established that most of the pastoralists (85\%) obtained seasonal climatic forecast information from primary sources such as radios, televisions and the internet. The two studies corroborate the findings of the present study of significance of the media and extension services.

The study finding indicates that local climate information sources have an effectiveness value of 0.81 in influencing the uptake of seasonal climate forecast, making it an important enabling environment. From the household survey, the respondents value local climate information sources because they are readily available especially for those who do not own radios, television or cannot access newspapers. Most parts of the study area has weak internet connection making it difficult for pastoralists to access climate forecasts through the internet. More so, the respondents depend on the climatic information they access from friends, relatives, neighbours, administration personnel (chiefs, sub-chiefs, etc). According to the respondents, since most household heads are concerned about the nature of the up-coming season, as the season approaches, conjectures about the likely rainfall/drought scenario constitute the most common topic in social encounters. Residents exchange greetings and often update one another on the climate situation of their respective villages, commonly and locally referred to as "eating news". [35] recorded similar findings in their study among the smallholder agro-pastoralists in Machakos District where they found that inter-per- 
sonal contacts were the most common source of climate forecast information due to the absence of other sources such as radio or television. It is therefore important to factor in the role of local climate information in developing effective approaches at improving uptake of seasonal climate forecasts.

\section{Conclusions}

The study assessment of conditions enabling better use of seasonal climate forecasts among pastoral communities aimed to answer the following research questions:

a) What are the barriers to use of seasonal climate forecasts?

b) Which are the enabling conditions for better use seasonal climate forecast in a pastoral community?

From the findings presented in this study, it is concluded that:

a) The factors/barriers with greater influence on uptake of seasonal climate forecast information were lack of information, access, diversified sources of income and insecurity/conflicts, illiteracy and culture.

b) The institutions/enabling conditions with large influence on uptake of seasonal climate forecast were knowledge dissemination linked to radio and extension services and local climate information. The study further indicate that local climate information plays significant role in uptake of scientific seasonal climate information.

\section{Recommendations}

The study identified barriers and enabling conditions to access and uptake of seasonal climate forecast. It therefore recommends investment in mass education on importance of formal schooling, initiatives by local leaders and government to encourage pastoralists to access education and retain children in school amongst others, an aim to address illiteracy in the study area. The Extension agencies and media should be empowered to enhance their capacity to dissemination and access of climate information in the study area. There is need to integrate local climate information with scientific climate in order to promote uptake of seasonal climate forecasts.

\section{References}

[1] Klopper, E., Vogel, C.H. and Landman, W.A. (2006) Seasonal Climate ForecastsPotential Agricultural-Risk Management Tools. Climate Change, 76, 73-90. https://doi.org/10.1007/s10584-005-9019-9

[2] Washington, R., Harrison, M., Conway, D., Black, E., Challinor, A., Grimes, D., Jones, R., Morse, A., Kay, G. and Todd, M. (2006) African Climate Change: Taking the Shorter Route. Bulletin of the American Meteorological Society, 87, 1355-1366. https://doi.org/10.1175/BAMS-87-10-1355

[3] FAO (2013) Climate-Smart Agriculture Sourcebook. http://www.fao.org/docrep/018/i3325e/i3325e.pdf

[4] Innovations in Climate Risk Management: Protecting and Building Rural Livelih- 
oods in a Variable and Changing Climate. Paper submitted for the ICRISAT $35^{\text {th }}$ Anniversary Symposium, "Climate-Proofing Innovation for Poverty Reduction and Food Security," 22-24 November 2007. Open Access Journal, 4.

[5] Lemos, M.C., Finan, T.J., Fox, R.W., Nelson, D.R. and Tucker, J. (2002) The Use of Seasonal Climate Forecasting in Policy Making: Lessons from Northern Brazil. Climate Change, 55, 479-507. https://doi.org/10.1023/A:1020785826029

[6] McIntyre, B. and Phillips, J. (2000) ENSO and Inter-Annual Rainfall Variability in Uganda: Implications for Agricultural Management. International Journal of Climatology, 20, 171-182.

https://doi.org/10.1002/(SICI)1097-0088(200002)20:2<171::AID-JOC471>3.0.CO;2$\underline{\mathrm{O}}$

[7] Recha, C.W., Shisanya, C.A., Makokha, G.L. and Kinuthia, R.N. (2008) Perception and Use of Climate Forecast Information amongst Smallholder Farmers in SemiArid Kenya. Asian Journal of Applied Sciences, 1, 128-135.

[8] Patt, A. and Gwata, C. (2002) Effective Seasonal Climate Forecast Applications: Examining Constraints for Subsistence Farmers in Zimbabwe. Global Environmental Change, 12, 185-195. https://doi.org/10.1016/S0959-3780(02)00013-4

[9] Chipanshi, A.C., Chanda, R. and Totolo, O. (2003) Vulnerability Assessment of the Maize and Sorghum Crops to Climate Change in Botswana, Climate Change, 61, 339-360. https://doi.org/10.1023/B:CLIM.0000004551.55871.eb

[10] Morton, J.F. (2007) The Impact of Climate Change on Smallholder and Subsistence Agriculture. Proceedings of the National Academy of Sciences, 104, 19680-19685. https://doi.org/10.1073/pnas.0701855104

[11] O’Brien, K. and Vogel, C.H. (2003) Coping with Climate Variability: User Responses to Seasonal Climate Forecasts in Southern Africa. Ashgate, Burlington.

[12] Republic of Kenya (2011) The Vision 2030 Development Strategy for Strategy Northern Kenya and Other Arid Lands. Government Printers, Nairobi.

[13] IPAR (2002) How Public Policy Can Improve the Situation of Kenyan Pastoralists, IPAR Policy Brief 8.3. IPAR.

[14] Jaetzold, R., Schmidt, H., Hornetz, B. and Shisanya, C. (2007) Farm Management Handbook of Kenya: Part C, East Kenya. 2, Ministry of Agriculture, Nairobi.

[15] Republic of Kenya (2013) Baringo County Budget Implementation Report. Government Printers, Nairobi.

[16] Republic of Kenya (2014) Baringo County Government Annual Development Plan 2015/16. Government Printers, Nairobi.

[17] Allamano, P., Seckler, D. and Makin, I.I. (2010) Estimating the Potential of RainFed Agriculture: Working Paper 20. International Water Management Institute, Colombo.

[18] Boko, M., Niang, I., Nyong, A., Vogel, C., Githeko, A., Medany, M., Osman-Elasha, B., Tabo, R. and Yanda, P. (2007) Climate Change 2007: Impacts, Adaptation and Vulnerability. Contribution of Working Group II to the Fourth Assessment Report of the Intergovernmental Panel on Climate Change. In: Parry, M.L., Canziani, O.F., Palutikof, J.P., van der Linden, P.J. and Hanson, C.E., Eds., Africa. Cambridge University Press, Cambridge, 433-467.

[19] World Bank (2013) Agricultural Sector Risk Assessment in Niger: Moving from Crisis Response to Long-Term Risk Management. Report No. 74322-NE. The World Bank, Washington DC. 
[20] Patt, A., Suarez, P. and Gwata, C. (2005) Effects of Seasonal Climate Forecasts and Participatory Workshops among Subsistence Farmers in Zimbabwe. Proceedings of the National Academy of Sciences of the United States of America, 102, 1262312628. https://doi.org/10.1073/pnas.0506125102

[21] Luseno, W.K., McPeak, J.G., Barrett, C.B., Little, P.D. and Gebru, G. (2003) Assessing the Value of Climate Forecast Information for Pastoralists: Evidence from Southern Ethiopia and Northern Kenya. World Development, 31, 1477-1494. https://doi.org/10.1016/S0305-750X(03)00113-X

[22] Kijazi, A.L., Chang'a, L.B., Liwenga, E.T., Kanemba, A. and Nindi, S.J. (2013) The Use of Indigenous Knowledge in Weather and Climate Prediction in Mahenge and Ismani Wards, Tanzania. Journal of Geography and Regional Planning, 6, 274. https://doi.org/10.5897/JGRP2013.0386

[23] UNEP (2008) Indigenous Knowledge in Disaster Management in Africa. UNEP, Nairobi.

[24] Reyes-García, V., Fernández-Llamazares, Á., Guèze, M., Garcés, A., Mallo, M., Vila-Gómez, M. and Vilaseca, M. (2016) Local Indicators of Climate Change: The Potential Contribution of Local Knowledge to Climate Research. Wiley Interdisciplinary Reviews. Climate Change, 7, 109-124. https://doi.org/10.1002/wcc.374

[25] Oucho, J.O. (2002) Undercurrents of Ethnic Conflicts in Kenya. Brill, Leiden.

[26] Njoroge, E.M. (2011) Church's Approaches to Peacebuilding and Reconciliation in Ethnic Conflict Areas in Kenya: A Case Study of Laikipia West District. Ph.D. Thesis, Kenyatta University, Kahawa, Nairobi.

[27] Anderson, D. (2002) Eroding the Commons: The Politics of Ecology in Baringo, Kenya, 1890s-1963. James Currey Publishers, Suffolk.

[28] Ajibade, L.T. and Shokemi, O.O. (2003) Indigenous Approach to Weather Forecasting in ASA LGA, Kwara State, Nigeria. Indilinga African Journal of Indigenous Knowledge Systems, 2, 37-44.

[29] Vogel, C. and O’Brien, K. (2006) Who Can Eat Information? Examining the Effectiveness of Seasonal Climate Forecasts and Regional Climate-Risk Management Strategies. Climate Research, 33, 111-122. https://doi.org/10.3354/cr033111

[30] Swanson, B.E. (2006) Seminal Article Series: The Changing Role of Agricultural Extension in a Global Economy. Urbana, 51, Article ID: 61801.

[31] Vogel, C. (2000) Usable Science: An Assessment of Long-Term Seasonal Forecasts amongst Farmers in Rural Areas of South Africa. South African Geographical Journal, 82, 107-116. https://doi.org/10.1080/03736245.2000.9713700

[32] Thomson, A. (2003) National Responses to Seasonal Forecasts in 1997. In: O'Brien, K. and Vogel, C., Eds., Coping with Climate Variability: The Use of Seasonal Climate Forecasts in Southern Africa. Ashgate Publishing Ltd, Farnham.

[33] Moser, S.C. and Dilling, L. (2004) Making Climate Hot. Environment. Science and Policy for Sustainable Development, 46, 32-46. https://doi.org/10.1080/00139150409605820

[34] Ziervogel, G. and Downing, T.E. (2004) Stakeholder Networks: Improving Seasonal Climate Forecasts. Climatic Change, 65, 73-101. https://doi.org/10.1023/B:CLIM.0000037492.18679.9e

[35] Ngugi, R.K., Mureithi, S.M. and Kamande, P.N. (2011) Climate Forecast Information: The Status, Needs and Expectations among Smallholder Agro-Pastoralists in Machakos District, Kenya. International Journal of Current Research, 3, 6-12.

[36] Keogh, D.U., Watson, I.W., Bell, K.L., Cobon, D.H. and Dutta, S.C. (2006) Climate 
Information Needs of Gascoyne-Murchison Pastoralists: A Representative Study of the Western Australian Grazing Industry. Animal Production Science, 45, 16131625. https://doi.org/10.1071/EA04275

Submit or recommend next manuscript to OALib Journal and we will provide best service for you:

- Publication frequency: Monthly

- 9 subject areas of science, technology and medicine

- Fair and rigorous peer-review system

- Fast publication process

- Article promotion in various social networking sites (LinkedIn, Facebook, Twitter, etc.)

- Maximum dissemination of your research work

Submit Your Paper Online: Click Here to Submit

Or Contact service@oalib.com 